\title{
The Prophylactic Effect of Pinocembrin Against Doxorubicin- Induced Cardiotoxicity in an In Vitro H9c2 Cell Model
}

\author{
Nonhlakanipho F. Sangweni ${ }^{1,2}$, Malebogo Moremane ${ }^{1,2}$, Sylvia Riedel ${ }^{1,2}$, \\ Derick van Vuuren ${ }^{2}$, Barbara Huisamen ${ }^{2}$, Lawrence Mabasa ${ }^{1}$, Reenen Barry ${ }^{3}$ \\ and Rabia Johnson ${ }^{1,2 *}$

\footnotetext{
${ }^{1}$ Biomedical Research and Innovation Platform (BRIP), South African Medical Research Council, Tygerberg, South Africa, ${ }^{2}$ Division of Medical Physiology, Faculty of Health Sciences, Stellenbosch University, Tygerberg, South Africa, ${ }^{3}$ Research and Development Department, Biopharm, Hamilton, New Zealand
}

OPEN ACCESS

Edited by: Bimal Malhotra,

Pfizer, United States

Reviewed by: Jessica Gambardella, University of Salerno, Italy Sandra Sigala, University of Brescia, Italy

${ }^{*}$ Correspondence: Rabia Johnson rabia.johnson@mrc.ac.za

Specialty section: This article was submitted to Cardiovascular and Smooth

Muscle Pharmacology,

a section of the journal

Frontiers in Pharmacology

Received: 06 December 2019

Accepted: 17 July 2020

Published: 05 August 2020

Citation:

Sangweni NF, Moremane M, Riedel S, van Vuuren $D$, Huisamen $B$, Mabasa $L$, Barry R and Johnson R (2020) The Prophylactic Effect of Pinocembrin Against Doxorubicin-Induced Cardiotoxicity in an In Vitro H9c2 Cell Model.

Front. Pharmacol. 11:1172. doi: 10.3389/fphar.2020.01172
Background: The clinical use of Doxorubicin (Dox) is significantly limited by its dosedependent cardiotoxic side effect. Accumulative evidence suggests that the use of flavonoids, such as the antioxidative Pinocembrin (Pin), could be effective in the prevention of Dox-induced cardiotoxicity. Accordingly, we investigated the ability of pinocembrin (Pin) to attenuate Dox-induced cardiotoxicity in an in vitro $\mathrm{H9c2}$ cardiomyoblast model.

Methodology: The cardioprotective potential of Pin was established in H9c2 cells. Here, cells were treated with Dox $(2 \mu \mathrm{M})$, Dox $(2 \mu \mathrm{M})+$ Pin $(1 \mu \mathrm{M})$, and Dox $(2 \mu \mathrm{M})+$ Dexrazoxane $(20 \mu \mathrm{M})$ for 6 days. Thereafter, the safe co-administration of Pin with Dox, in a cancer environment, was investigated in MCF-7 breast cancer cells subjected to the same experimental conditions. Untreated cells served as the control. Subsequently, Pin's ability to attenuate Dox-mediated oxidative stress, impaired mitochondrial bioenergetics and potential, as well as aggravated apoptosis was quantified using biochemical assays.

Results: The results demonstrated that co-treatment with Pin mitigates Dox-induced oxidative stress by alleviating the antioxidant enzyme activity of the $\mathrm{H} 9 \mathrm{c} 2$ cells. Pin further reduced the rate of apoptosis and necrosis inferred by Dox by improving mitochondrial bioenergetics. Interestingly, Pin did not decrease the efficacy of Dox but, rather increased the rate of apoptosis and necrosis in Dox-treated MCF-7 cells.

Conclusion: The findings presented in this study showed, for the first time, that Pin attenuates Dox-induced cardiotoxicity without reducing its chemotherapeutic effect. We propose that additional studies, using in vivo models, should be conducted to further investigate Pin as a suitable candidate in the prevention of the cardiovascular dysfunction inferred by Dox administration.

Keywords: doxorubicin, cardiotoxicity, pinocembrin, antioxidants, mitochondrial bioenergetics, apoptosis 


\section{INTRODUCTION}

Doxorubicin (Dox) is a highly potent chemotherapeutic drug that is actively used in the treatment of numerous malignancies like metastatic breast cancer, however, the clinically use of Dox is hindered by a dose-dependent cardiotoxic side effect (Koleini and Kardami, 2017; Zilinyi et al., 2018). This has been confirmed in various studies including studies conducted by Harake et al. (2012) and Zilinyi et al. (2018) who argued that while the use of Dox increased life expectancy, its use as a chemotherapeutic agent was limited.

While the molecular signaling pathways underlying the cardiotoxic side-effects of Dox remain obscure, several theories including mitochondrial dysfunction, increased reactive oxygen species (ROS) production and aggravated apoptosis have been proposed as plausible underlying mechanisms (Carvalho et al., 2009; McGowan et al., 2017). Singal and Kirshenbaum (1990) suggested that a possible strategy to prevent Dox-induced cardiotoxicity would be to target these pathways and introduce additional antioxidant therapy to Dox treatment. However, in the case of cancer cells they exhibit higher basal oxidative stress relative to normal cells and consequently take advantage of the upregulated antioxidant system to circumvent ROS-mediated tumor cell damage (Raninga et al., 2014; Bernardes et al., 2015; Thyagarajan and Sahu, 2018). Additionally, Yasueda and colleagues (2016) argued that while antioxidant therapies are capable of alleviating the adverse effects of chemotherapy, they could antagonize the antitumor effects by reducing oxidative damage. Thus, it is imperative to clarify whether or not newly developed therapeutic adjuncts interact with cancer therapy. Currently, the only FDA approved cardioprotective agent used to reduce the burden inferred by Dox on the myocardium is Dexrazoxane (Dex) (Vachhani et al., 2017). Initially, the use of Dex was surrounded by controversy possibly because of concerns of its potential impact on chemotherapy efficacy and the risk of secondary malignant neoplasms (Kosty et al., 2001; Levis et al., 2017; Tahover et al., 2017). However, a metaanalysis by van Dalen et al. (2011) reported that Dex provided a benefit on heart failure with a risk ratio of 0.29 and no deleterious effect on the overall survival. Nonetheless, on the basis of these findings, the European Medicines Agency has since restricted the use of Dex to adult patients and contraindicating its use in pediatric patients. This therefore, necessitates the need to investigate alternative treatment to use as adjuncts to current chemotherapeutic drugs (Ganatra et al., 2019).

Such a treatment could be Pinocembrin (Pin, 5,7dihydroxyflavanone), which is an antioxidative flavanone (Lungkaphin et al., 2015; Ahmeda et al., 2017) that has been identified in propolis and several plants, such as Galenia africana, and is reported to have anti-cancer and cardioprotective properties (Rasul et al., 2013). Although a direct link between antioxidants and the modulation of cancer immunoediting has not been fully established, evidence suggests that flavonoids may be able to modulate immunoediting processes like restoring cancer immune surveillance which may be helpful in eradicating cancer cells
(Bhattacharyya et al., 2010; Bose et al., 2015). Additionally, such flavonoids have been demonstrated to play a crucial role in mitigating the cardiotoxic effects inferred by Dox administration (Bast et al., 2007; Sun et al., 2007; Chang et al., 2019). In the case of Pin, its ability to regulate inflammatory cytokines, improve mitochondrial function whilst inhibiting platelet aggregation and mitigating apoptosis in the cardiac muscle makes it a suitable candidate in the prevention of Dox-induced cardiotoxicity (Saad et al., 2015; Shen, 2019). Pinocembrins' cardioprotective potential is further endorsed by its vasorelaxant (Estrada et al., 2020) effects which could aid in the preservation of cardiac function by alleviating cardiac fibrosis and left ventricular dysfunction (Rasul et al., 2013; Borriello et al., 2019), which is a hallmark for Dox-induced cardiotoxicity. Literature suggests that $\mathrm{H} 9 \mathrm{c} 2$ cells are a suitable model to study the effects of Dox-induced cardiotoxicity in an in vitro setting, as it has been shown that the major adverse effects reported in patients exposed to Doxcan be induced in these cells (Catanzaro et al., 2019; Dallons et al., 2020; Faridvand et al., 2020; Hu et al., 2020). Hence, the objective of the current study was to i) assess the prophylactic effect of Pin against the cardiotoxicity inferred by Dox administration using an $\mathrm{H} 9 \mathrm{c} 2$ cardiomyoblast model, as well as ii) to evaluate the effect of Pin on the chemotherapeutic potential of Dox in an MCF-7 breast cancer cell line.

\section{MATERIALS AND METHODS}

\section{Preparation of Pinocembrin, Doxorubicin, and Dexrazoxane}

Stock solutions of Pinocembrin (MW: $256.25 \mathrm{~g} / \mathrm{mol}$ ) (Pin, 10 $\mathrm{mM}$, BioPharm ${ }^{\mathrm{TM}}$, New Zealand) and Dexrazoxane (MW: $268.269 \mathrm{~g} / \mathrm{mol}$ ) (Dex, $1 \mathrm{mM}$ ) (Sigma-Aldrich, St Louis, MO, USA) were prepared in Dimethyl sulfoxide (DMSO, SigmaAldrich, Saint Louis, MO, USA). DMSO concentration was kept below 0.0001\%. Doxorubicin hydrochloride (MW: 579.98 $\mathrm{g} / \mathrm{mol}$ ) (Dox, $1 \mathrm{mM}$ ) was prepared in tissue culture (TC) grade water. Thereafter, final concentrations of $1 \mu \mathrm{M}$ (Pin), $20 \mu \mathrm{M}$ (Dex) and $2 \mu \mathrm{M}$ (Dox) were prepared in Dulbecco's modified Eagle medium without phenol red (DMEM, Lonza, Walkersville, MD, USA) supplemented with $2 \%$ fetal bovine serum (FBS, Thermo Fisher Scientific, Waltham, MA, USA) and then filter sterilized using $0.22 \mu \mathrm{M}$ syringe filter systems prior to commencing treatment. Doses for Dox and Dex were derived from the clinically recommended therapeutic ratio of 1:10 (Rharass et al., 2016), while the concentration used for Pin was extrapolated from our preliminary dose response findings.

\section{H9c2 Cardiomyoblasts}

Rat heart ventricular derived $\mathrm{H} 9 \mathrm{c} 2$ cardiomyoblasts are immortalized cells with a cardiac phenotype and have been extensively used as a screening tool for novel therapeutic agents and to investigate the effects of Dox-induced cardiotoxicity (Dallons et al., 2020; Hu et al., 2020). The 
H9c2 cells were purchased from the American Type Culture Collection (ATCC, catalogue number CRL-1446). Briefly, H9c2 cells were cultured in Dulbecco's modified Eagle medium (DMEM, Lonza, Walkersville, MD, USA) supplemented with $10 \%$ FBS under standard tissue culture (TC) conditions $\left(37^{\circ} \mathrm{C}, 95 \%\right.$ humidified air and $\left.5 \% \mathrm{CO}_{2}\right)$. Cells were passaged regularly at $80-90 \%$ sub-confluence and were seeded in 96-well $\left(0.8 \times 10^{5}\right.$ cells/well $), 24$-well $\left(1 \times 10^{5}\right.$ cells/ well), or 6 -well plates $\left(2 \times 10^{5}\right.$ cells/well). To attain the most therapeutic dose, $\mathrm{H} 9 \mathrm{c} 2$ cells were exposed to log concentrations $(0.01-1,000 \mu \mathrm{M})$ of Pin, for 6 days. The therapeutic dose was determined as the dose that would increase cell viability in the H9c2 cells. Thereafter, chronic cardiotoxicity was induced by exposing the H9c2 cells with 2 $\mu \mathrm{M}$ Dox. The prophylatic effect of Pin against Dox-induced cardiotoxicity was determined by co-treating the cells with Dox $(2 \mu \mathrm{M})$ plus Pin $(1 \mu \mathrm{M})$. H9c2 cells co-treated with Dox (2 $\mu \mathrm{M})$ plus Dex $(20 \mu \mathrm{M})$ served as a positive control. Untreated cells served as the control group. H9c2 cells were treated every second day for 6 days and experiments conducted on day 7 .

\section{MCF-7 Breast Cancer Cells}

Human metastatic breast cancer derived MCF-7 cells are estrogen receptor positive and are often used in vitro to study estrogen receptor positive breast cancers (Vantangoli et al., 2015). MCF-7 cells were purchased from the American Type Culture (ATC, catalogue number HTB-22) and cultured in DMEM supplemented with $10 \%$ FBS, under standard TC conditions. Similar to the H9c2 cells, MCF-7 breast cancer cells were exposed to log concentrations $(0.01-1,000 \mu \mathrm{M})$ of Pin to ensure that the selected therapeutic dose for the H9c2 cells would not stimulate cell proliferation in the MCF-7 cells. Thereafter, as a proof concept, cells were treated with Dox $(2 \mu \mathrm{M})$. To assess whether the chemotherapeutic effect of Dox was maintained, cells were also co-treated with Dox $(2 \mu \mathrm{M})$ plus Pin $(1 \mu \mathrm{M})$ as well as Dox $(2 \mu \mathrm{M})$ plus Dex $(20 \mu \mathrm{M})$. To assess the anti-cancer effect of Pin, cells were treated with $1 \mu \mathrm{M}$ Pin alone. Untreated cells served as the control. Cells were treated every second day for 6 days and experiments conducted on day 7 .

\section{Assessment of Cell Viability}

Cell viability was assessed by conducting an MTT [3-[4,5dimethylthiazole-2-yl]-2,5-diphenyltetrazolium bromide dye (Sigma-Aldrich, St Louis, MO, USA)] assay using an in-house protocol. Briefly, after 6 days of treatment, the treatment media was aspirated and the $\mathrm{H} 9 \mathrm{c} 2$ cells were stained with $100 \mu \mathrm{l}$ of the MTT dye $(2 \mathrm{mg} / \mathrm{ml}$ MTT dissolved in Dulbecco's phosphatebuffered saline). To facilitate the reaction, stained cells were incubated for 30 minutes ( $\mathrm{min}$ ), under standard TC conditions. Thereafter, the MTT dye was discarded and replaced with $200 \mu \mathrm{l}$ DMSO and $25 \mu \mathrm{l}$ ice cold Sorenson's buffer. Cells were then incubated for $5 \mathrm{~min}$ at room temperature (RT), before reading the absorbance $(570 \mathrm{~nm})$ with a BioTek ${ }^{\circledR}$ ELx600 plate reader (Bio-Tek Instruments, Inc., Winooski, VT, USA using Gen $5^{\circledR}$ software).

\section{Determination of Metabolic Activity}

Cytoplasmic levels of ATP production was quantified using a ViaLight plus ATP assay kit (Lonza, Walkersville, MD, USA) as per the manufacturer's instructions. Briefly, $140 \mu \mathrm{l}$ of treatment media from H9c2 and MCF-7 cells, previously seeded in white 96 well plates, was discarded leaving a volume of $60 \mu \mathrm{l}$ in each well. To this, an additional $60 \mu \mathrm{l}$ of the ATP cell lysis reagent was pipetted into each well, followed by $10 \mathrm{~min}$ incubation under standard TC conditions. Subsequently, protein concentration was quantified as described in 2.4.1. Next, $100 \mu \mathrm{l}$ of the ATP monitoring reagent was pipetted into cell lysates and then incubated for an additional $5 \mathrm{~min}$ RT. Luminescence, as measurement of metabolic activity, was measured on the BioTek ${ }^{\circledR}$ FLx800 plate reader using the Gen 5 software ${ }^{\circledR}$ (BioTek Instruments, Inc., Winooski, VT, USA). Cellular metabolic activity was normalized against the protein data.

\section{Quantifying Protein Concentration}

Total protein concentration was measured using the Bradford assay which relies on the formation of a complex between Coomassie brilliant blue G-250 dye and proteins in solution. Briefly, $5 \mu \mathrm{l}$ of cell lysates from previously treated cells was transferred into a new 96 well plate. Thereafter, $180 \mu \mathrm{l}$ of the Bradford reagent was pipetted into the cell lysates and then incubated at RT for $5 \mathrm{~min}$. The protein concentration was determined by the amount of blue ionic dye measured by the absorbance of the cell lysate solution at $595 \mathrm{~nm}$ using the Gen 5 software $^{\circledR}$ (Bio-Tek Instruments, Inc., Winooski, VT, USA).

\section{Quantification of Reactive Oxygen Species (ROS) Production}

Intracellular production of reactive oxygen species (ROS) was determined using an OxiSelect ${ }^{\mathrm{TM}}$ Intracellular ROS assay kit (Cell Biolabs, San Diego, USA). After 6 days of treatment, media was aspirated and the $\mathrm{H} 9 \mathrm{c} 2$ cells were washed with pre-warmed Dulbecco's phosphate-buffered saline (DPBS, Lonza, Walkersville, MD, USA) before being stained with $100 \mu \mathrm{l}$ of DCFH-DA $(20 \mu \mathrm{M})$ staining solution. Thereafter, the stained cells were incubated under standard TC conditions for $30 \mathrm{~min}$. Following incubation, the DCFH-DA staining solution was discarded and the cells were reconstituted in $100 \mu \mathrm{l}$ of Hank's Balanced Salt Solution (HBSS, Sigma-Aldrich, St Louis, MO, USA). ROS activity was then quantified by measuring the fluorescent intensity of DCFH-DA at excitation and emission wavelengths of $485 \pm 20 \mathrm{~nm} / 528 \pm 20 \mathrm{~nm}$ using a BioTek FLx800 plate reader and analysed with Gen $5^{\circledR}$ software.

\section{The Assessment of Lipid Peroxidation}

Lipid peroxidation was quantified by measuring the production of malondialdehyde (MDA) using an OxiSelect ${ }^{\mathrm{TM}}$ thiobarbituric acid (TBA) reactive substances (TBARS) assay Kit (Cell Biolabs, San Diego, USA). To account for the detached cells following treatment exposure, the supernatant of cells previously seeded in 6 well plates was collected into $15 \mathrm{ml}$ tubes before washing the cells with prewarmed DPBS. The cells were then trypsinized, centrifuged and collected into $2 \mathrm{ml}$ eppendorf tubes at a cell suspension of 
approximately $1 \times 10^{7}$. The cell suspension was then re-suspended in PBS containing $1 \mathrm{X}$ butylated hydroxytoluene (BHT) before being homogenized with an ice cold Qiagen TissueLyser block (Qiagen, Hilden, Germany) for $1 \mathrm{~min}$. A dilution series $(125 \mu \mathrm{M}-0 \mu \mathrm{M})$ of MDA standards were prepared by diluting the MDA Standard, provided in the TBARS kit, in deionized water. Subsequently, $100 \mu \mathrm{l}$ of the cell lysates and MDA standards were transferred into new eppendorf tubes followed by the addition of $100 \mu \mathrm{l}$ of sodium dodecyl sulfate lysis solution and mixed thoroughly. The samples were then incubated for 5 mins at RT. Thereafter, $250 \mu \mathrm{l}$ of TBA reagent was added to each sample and then incubated at $95^{\circ} \mathrm{C}$ on a heating block for $60 \mathrm{~min}$. Following incubation, the tubes were chilled to RT in an ice bath for $5 \mathrm{~min}$ and the samples were centrifuged at 3,000 rpm for $15 \mathrm{~min}$. Thereafter, $150 \mu \mathrm{l}$ of the MDA standard and sample supernatant was transferred into a 96 well black fluorescence plate. Fluorometric measurement was read at an excitation of $540 \mathrm{~nm}$ and emission of $590 \mathrm{~nm}$.

\section{Quantification of Superoxide Dismutase Activity}

The activity of the antioxidant superoxide dismutase (SOD) was measured using a colorimetric SOD activity assay kit (Abcam, Pretoria, SA) as per the manufacturer's instructions. Briefly, cell suspensions were prepared as described in section 1.6. The cells were lysed with $100 \mu \mathrm{l}$ of $0.1 \mathrm{M}$ trizma/hydrochloride (Tris/ $\mathrm{HCl})$, [comprising of $0.5 \%$ Triton X-100, $5 \mathrm{mM} \beta$-methylphenethylamine ( $\beta$-ME) and $0.1 \mathrm{mg} / \mathrm{ml}$ phenylmethylsulfonyl fluoride (PMSF) at a $\mathrm{pH}$ of 7.4] and then transferred into $2 \mathrm{ml}$ eppendorf tubes. Cell lysates were then centrifuged at $15,000 \mathrm{x}$ g for $5 \mathrm{~min}$ at $4^{\circ} \mathrm{C}$. Thereafter, $20 \mu \mathrm{l}$ of the supernatants was pipetted into a new 96 well assay plate and to this, $200 \mu \mathrm{l}$ of the 2-(4-iodophenyl)-3-(4nitrophenyl)-5-(2,4-disulfo-phenyl)-2H-tetrazolium, monosodium salt (WST) working solution and $20 \mu \mathrm{l}$ of the enzyme working solution was added to the supernatants. The plates were then incubated at $37^{\circ} \mathrm{C}$ for $20 \mathrm{~min}$. After incubation, SOD activity was measured on the Biotek ${ }^{\circledR}$ ELX 800 plate reader (Gen $5^{\circledR}$ software) at an absorbance rate of $450 \mathrm{~nm}$.

\section{Quantification of Total Glutathione Content}

The GSH/GSSH-Glo ${ }^{\text {TM }}$ assay kit (Promega, Madison, Wilsconsin, USA) is a quantitative assay that encompasses both reduced (GSH) and oxidized glutathione (GSSG) and was used to quantify total glutathione content of $\mathrm{H} 9 \mathrm{c} 2$ cells and MCF-7 breast cancer cells seeded in white 96 well plates, as per the manufacturer's protocol. Following treatment, media was aspirated and then cells were lysed with $50 \mu$ of either GSH or GSSG lysis reagent. To facilitate the lysis reaction, plates were incubated at RTon an orbital shaker for $5 \mathrm{~min}$. Thereafter, $50 \mu \mathrm{l}$ of the Luciferin generation reagent was added to each well containing the cell lysates and then incubated under standard TC conditions for $30 \mathrm{~min}$. After incubation, $100 \mu \mathrm{l}$ of the luciferin detection reagent was pipetted into each well and then equilibrated for 15 min under standard TC conditions. Relative luminescence unit (RLU) was measured using the SpectraMax i3x ${ }^{\circledR}$ Multi-Mode Microplate Reader. Total GSH content was measured as the ratio of GSH/GSSG using the following formula:

Ratio of GSH $/$ GSSG $=\frac{(\text { Net treated GSH RLU }- \text { Net treated GSSG RLU) }}{(\text { Net treated GSSG } / 2)}$

\section{Mitochondrial Bioenergetics}

The oxygen consumption rate (OCR) and extracellular acidification rate (ECAR) of intact $\mathrm{H} 9 \mathrm{c} 2$ cells were measured using a Seahorse XF96 extracellular flux analyzer (Seahorse Bioscience, Billerica, MA, USA). Briefly, $80 \mu \mathrm{L}$ of single-cell suspensions of $\mathrm{H} 9 \mathrm{c} 2$ cells were plated in XF96 cell culture microplates (Seahorse Bioscience) at a cellular density of $1 \times 10^{4}$ and $5 \times 10^{3}$ per well, respectively. After $48 \mathrm{~h}$, cells were treated as per the treatments conditions described in section 1.2 for 6 days. On the day of the assay, cells were incubated in base assay medium supplemented with $2 \mathrm{mM}$ glutamine, $10 \mathrm{mM}$ glucose, and $1 \mathrm{mM}$ pyruvate for $1 \mathrm{~h}$, prior to the OCR and ECAR measurements using the XF Cell Mito Stress Kit (Seahorse Bioscience), as per the manufacturer's instructions. Mitochondrial OCR was measured over a period of $86 \mathrm{~min}$ over which time $1 \mu \mathrm{M}$ oligomycin (ATPsynthase inhibitor), $0.75 \mu \mathrm{M}$ FCCP (a mitochondrial uncoupler), and $5 \mu \mathrm{M}$ rotenone (complex I inhibitor) plus $5 \mu \mathrm{M}$ antimycin $\mathrm{A}$ (complex III inhibitor) were sequentially added to each well at specified time points. All compound injection solutions were prepared at a concentration $10 \mathrm{x}$ higher than the required finale concentration.

Data were normalized according to total protein content to control for the variation in cell number between Dox and Pin treated cells as well as control groups. On completion of the XF assay, H9c2 cells were lysed with $100 \mu \mathrm{l}$ of cell lysis reagent and protein concentration determined using the Bradford reagent. Protein concentrations were derived by reference to a bovine serum albumin (BSA) standard curve. The OCR data were expressed as $\mathrm{pmol} / \mathrm{min} / \mathrm{mg}$ protein and ECAR as $\mathrm{mpH} / \mathrm{min} /$ mg protein.

\section{Evaluation of Mitochondrial Membrane Potential}

Mitochondrial membrane potential (MMP) was assessed by staining cells with the cationic dye 5,5,6,6'-tetrachloro-1,1',3,3tetraethylbenzimidazolyl-carbocyanine iodide (JC-1, SigmaAldrich, St Louis, MO, USA) as per the manufactures instructions. Briefly, treatment media from $\mathrm{H} 9 \mathrm{c} 2$ and MCF-7 cells, previously seeded in black 96 well plates, was aspirated and the cells were washed twice with pre-warmed DPBS. Thereafter, cells were stained with $100 \mu \mathrm{l}$ of JC-1 dye at a concentration of 15.4 $\mu \mathrm{M}$ followed by a $45 \mathrm{~min}$ incubation under standard TC conditions. After incubation, the JC-1 dye was discarded and the cells washed with $100 \mu \mathrm{l}$ DPBS. Mitochondrial integrity was quantified by measuring the fluorescence intensity of J-aggregates, which is an indication of high MMP and is emitted as red fluorescence at $~ 590$ $\mathrm{nm}$, and JC-1 monomers, which indicates low MMP and is emitted as green fluorescence at $\sim 529 \mathrm{~nm}$, using a BioTek ${ }^{\circledR}$ FLx 800 plate reader. Data was normalized by fluorescence imaging using a Nikon inverted fluorescence microscope. 


\section{Evaluation of Apoptosis: Quantification of Annexin $\mathbf{V}$ and Propidium lodide}

Annexin V-FITC (Invitrogen, Carlsbad, CA, USA) and propidium iodide (PI, Sigma-Aldrich, St Louis, MO, USA) were used to detect early and late apoptosis as well as necrosis in H9c2 and MCF-7 cells, respectively. Briefly, cells that were previously treated in 24 well plates were harvested by collecting the supernatant (containing the detached cells) into $15 \mathrm{ml}$ centrifuge tubes and by trypsinization, i.e. $200 \mu \mathrm{l}$ trypsin was pipetted to the cells and then incubated for 5 min under standard TC conditions. Trypsinization was deactivated by adding $500 \mu \mathrm{l}$ of DPBS supplemented with 10\% FBS (staining buffer). The combined cell suspension (supernatant plus the trypsinized cells) was centrifuged at $300 \mathrm{~g}$ for $5 \mathrm{~min}$. Subsequently, the supernatant was decanted and the cells were re-suspended in $150 \mathrm{ul}$ of staining buffer before being transferred into $2 \mathrm{ml}$ eppendorf tubes. The H9c2 and MCF-7 cells were then stained with $1.5 \mu \mathrm{l}$ of Annexin V and $1 \mu \mathrm{l}$ of PI $(2 \mu \mathrm{g} / \mathrm{ml})$ staining solution. Stained H9c2 cells were incubated in the dark for $10 \mathrm{~min}$, while the MCF7 cells were incubated in the dark for $20 \mathrm{~min}$. After incubation, cells were acquired using a BD Accuri C6 flow cytometer (BD Biosciences) using the BD Accuri C6 Annexin V-FITC/PI template. Live, early and late apoptotic, and necrotic cells were analyzed with the BD Accuri C6 software using the FITC signal detector FL1 (excitation $=488 \mathrm{~nm}$; emission $=530 \mathrm{~nm}$ ) for Annexin V positive cells and FL3 detector (excitation $=488$ $\mathrm{nm}$; emission $=670 / \mathrm{LP}$ ) for PI positive cells.

\section{Statistical Analysis}

All data was statistical analyzed using GraphPad Prism software version 5.0 (GraphPad Software, Inc. La Jolla, USA). The data are represented as the mean \pm standard error of mean (SEM) of three independent biological experiments, with each experiment containing at least six replicates. Comparisons between treatment groups were performed using one-way analysis of variance (ANOVA), followed by a Tukey post hoc test and a student's t-test. A $p$ value of $\leq 0.05$ was considered as statistically significant.

\section{RESULTS}

\section{Cytotoxicity Effect of Pinocembrin}

To attain the most effective therapeutic dose of Pin, cell viability, using the MTT assay, was quantified to ensure that the selected dose (i) would not be toxic to the H9c2 cardiomyoblasts and (ii) would not increase the proliferation of the MCF-7 breast cancer cells. Our findings showed no significant change in the viability of the H9c2 and MCF-7 cells from concentrations 0.01-10 $\mu \mathrm{M}$ after 6 days of treatment versus the control group. However, a significant increase in cytotoxicity was observed at 100 and 1,000 $\mu \mathrm{M}$ in both cell lines. When we compared the effect of Pin between the two cell lines, we observed a significant difference in viability at a dose of $1 \mu \mathrm{M}$, as demonstrated by an increase in the number of viable $\mathrm{H} 9 \mathrm{c} 2$ cells with a concomitant decrease in viable MCF-7 cells. Based on these findings a dose $1 \mu \mathrm{M}$ was selected for all subsequent experiments (Figure 1A).

Next, we assessed the co-administrative effect of Dox plus Pin on the H9c2 cells against Dox-induced cytotoxicity. A significant loss in cell viability was observed in Dox-treated cells versus the control group $(24.89 \pm 1.38 \%$ versus $100 \pm 3.92 \%, \mathrm{p}=0.0001)$. No noticeable effect was observed in normal cells treated with Pin $(100.80 \pm 3.93 \%$ compared to $100.00 \pm 3.92 \%, p \geq 0.05)$. However, co-treatment with Dox plus Pin significantly attenuated $(46.93 \pm 3.32 \%, p \leq 0.001)$ Dox-induced cytotoxicity. Cytoprotection was also sustained in $\mathrm{H} 9 \mathrm{c} 2$ cells co-treated with Dox plus Dex $(42.27 \pm 2.48 \%, \mathrm{p} \leq 0.001)$ when compared to cells treated with Dox alone (Figure 1B).

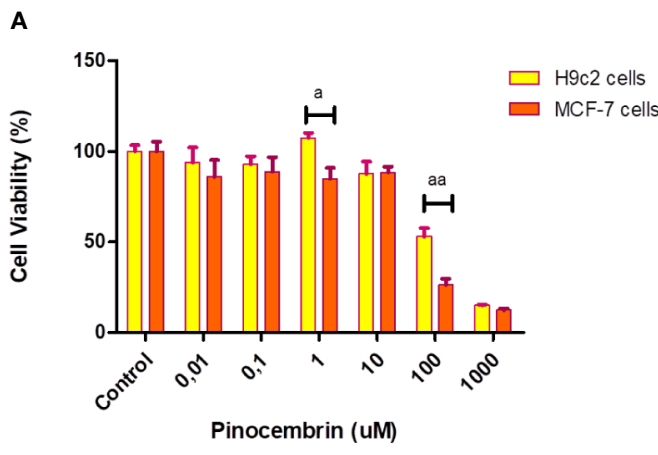

B

FIGURE 1 | The effect of pinocembrin (Pin) and the co-administrative effect of doxorubicin (Dox) plus Pin on cell viability. (A) Cytotoxicity effect of Pin on H9c2 cardiomyoblasts and MCF-7 breast cancer cells. (B) Co-administrative effect of Dox plus Pin on Dox-induced cardiotoxicity. Briefly, H9c2 and MCF-7 cells were exposed to log concentration $(0.01-1,000 \mu \mathrm{M})$, of Pin for 6 days to attain the most therapeutic dose. Thereafter, chronic cardiotoxicity was induced by subjecting the H9c2 cells to Dox $(2 \mu \mathrm{M})$ for 6 days. Cells were also co-treated with Dox $(2 \mu \mathrm{M})$ plus Pin $(1 \mu \mathrm{M})$ and Dox $(2 \mathrm{uM})$ plus Dexrazoxane (Dex) $(20 \mu \mathrm{M})$ or treated with Pin (1 $\mu \mathrm{M})$ for the same treatment duration. Untreated cells served as the control. The results were analyzed using One-way Anova, student t-tests, or non-parametric tests where applicable. Data are presented as the mean \pm SEM of 5 biological experiments with 3 technical repeats $(n=15)$. Significance is indicated as ${ }^{a} p \leq 0.05$, ${ }^{a a} p \leq$ 0.01 , versus the $\mathrm{H} 9 \mathrm{c} 2$ cells, ${ }^{\# \# \#} \mathrm{p} \leq 0.001$ versus the control and ${ }^{\star \star *} \mathrm{p} \leq 0.001$ versus Dox. 


\section{Co-Treatment With Pinocembrin Attenuates Doxorubicin-Induced Oxidative Stress}

In cardiac cells, Dox triggers mitochondria-dependent apoptosis primarily by inducing oxidative stress. Accordingly, Doxinduced ROS production in the H9c2 cells was quantified with DCFH-DA fluorogenic dye. As demonstrated in Figure 2A, the level of ROS activity increased significantly in Dox-treated H9c2 cells when compared to the control group (36.96 \pm 4.35 compared to $18.43 \pm 1.28 ; \mathrm{p} \leq 0.01)$. Whereas, co-treatment with Dox plus Pin $(28.78 \pm 3.03, \mathrm{p} \leq 0.01)$ was able to significantly attenuate Dox-induced oxidative stress. As an oxidative damage parameter, lipid peroxidation, as demonstrated by malondialdehyde (MDA) was found to be significantly augmented in the Dox group $(79.50 \pm 1.21, \mathrm{p} \leq 0.001)$ but, was expressively alleviated in cells co-treated with Dox plus Pin $(36.50 \pm 1.33 ; \mathrm{p} \leq 0.001)$ (Figure 2B). Additionally, cells cotreated with Dox plus Dex also presented with reduced ROS production $(25.09 \pm 2.45 ; \mathrm{p} \leq 0.01)$ and MDA content $(42.83 \pm$ $3.85 ; \mathrm{p} \leq 0.001)$. No notable effect in ROS activity $(20.69 \pm 1.54, \mathrm{p}$ $=0.28)$ and MDA content $(32.17 \pm 1.07 ; \mathrm{p}=0.06)$ was observed in cells treated with Pin alone.

\section{Pinocembrin Ameliorates Antioxidant Enzyme Activity in H9c2 Cells}

As a confirmation of Dox-induced oxidative stress, a significant decrease in superoxide dismutase (SOD) activity (29.61 \pm 3.14 versus $100.00 \pm 7.41 \%$ to, $\mathrm{p} \leq 0.001)$, reduced glutathione $(\mathrm{GSH})$ and total glutathione content (ratio of GSH/GSSG) $(7.13 \pm 1.01$ versus $24.21 \pm 0.712 ; \mathrm{p}=0.001)$ was demonstrated by Doxtreated $\mathrm{H} 9 \mathrm{c} 2$ versus the control (Figures 3A-D). However, Doxinduced oxidative stress was significantly ameliorated by Dox plus Pin as presented by increased SOD activity $(61.11 \pm 1.57 \%$, $\mathrm{p} \leq 0.01)$ and total glutathione content $(17.43 \pm 1.77, \mathrm{p} \leq 0.001)$. Additionally, cells co-treated with Dox plus Dex also had increased SOD activity (52.95 $\pm 1.35 ; \mathrm{p} \leq 0.05)$ and GSH/ GSSG content $(18.37 \pm 1.57, \mathrm{p} \leq 0.001)$. Treatment with Pin had no notable effect on the antioxidant levels [92.22 \pm 2.02 (SOD) and $24.33 \pm 0.08$ (GSH/GSSG)] (Figures 3A, D).

\section{Effect of Pinocembrin on the Antioxidant Capacity of MCF-7 Cells}

In cancer studies, high levels of antioxidants have been shown to offer a survival advantage in in vitro and in vivo models. Therefore, the notion that ROS are bad and antioxidants are good depends, to some extent, on context. Here, Dox-treated MCF-7 breast cancer cells were primarily characterized by a substantial increase in GSSG levels and a considerable reduction in GSH and GSH/GSSG content $(11.17 \pm 0.48$ versus $25.55 \pm$ $0.81 ; \mathrm{p} \leq 0.001$ ) (Figures 4A-C). While Dox plus Pin improved the antioxidant capacity of the H9c2 cells (Figures 3A-D), the co-treatment had no significant effect on the MCF-7 cells total glutathione content $(11.66 \pm 0.633 ; \mathrm{p} \leq 0.55)$ versus the cells treated with Dox alone (Figures 4A, C). These findings suggest that Dox plus Pin may facilitate the accumulation of ROS in the metastatic MCF-7 cells. In addition, cells treated with Pin presented with a significant reduction in total glutathione content $(22.03 \pm 1.27 ; \mathrm{p} \leq 0.001)$ when compared to the control. Interestingly, co-treatment with Dox plus Dex had a significant effect on Dox-induced oxidative stress as demonstrated by the increased antioxidant status (15.96 \pm 0.68 ; $\mathrm{p} \leq 0.01)$ of the metastatic MCF-7 breast cancer cells.

\section{Pinocembrin Improves Mitochondrial Bioenergetics in H9c2 Cells}

OCR and extracellular acidification rate (ECAR) were evaluated to ascertain whether the mitochondria of Dox-treated H9c2 cells had defective mitochondrial bioenergetics. Real-time OCR revealed that basal respiration (15.37 \pm 0.25 relative to $48.06 \pm 1.02 ; \mathrm{p} \leq 0.05)$,
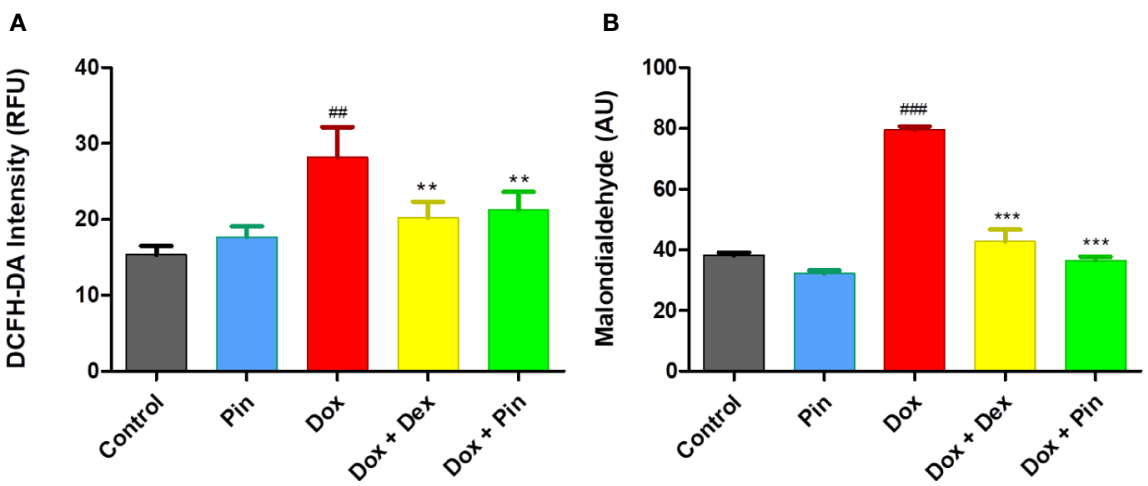

FIGURE 2 | The effect of pinocembrin (Pin) on doxorubicin (Dox)-induced oxidative stress. (A) ROS production was quantified using a fluorogenic dye (2,7dichlorofluorescin diacetate (DCFH-DA) which measures hydroxyl and peroxyl radicals. (B) Lipid peroxidation was quantified by measuring the malondialdehyde (MDA) which reacts with thiobarbituric acid (TBA) to generate an MDA-TBA adduct. H9c2 cells were treated with Dox ( $2 \mu \mathrm{M})$, Pin ( $\mu$ M), Dox (2 $\mu \mathrm{M})$ plus Pin ( $\mu \mathrm{M})$ and Dox plus Dex $(20 \mu \mathrm{M})$ for 6 days. The results were analyzed using One-way Anova, student t-tests, or non-parametric tests where applicable. Data are shown as the mean \pm SEM of 3 biological experiments with 3 technical repeats $(n=9)$. Significance is indicated as ${ }^{\# \#} p \leq 0.01$, ${ }^{\# \# \#} p \leq 0.001$ versus the control; ${ }^{* *} p \leq 0.01$, ${ }^{\star \star \star} \mathrm{p} \leq 0.001$ versus Dox. Relative fluorescence units (RFU). Arbitrary units (AU). 

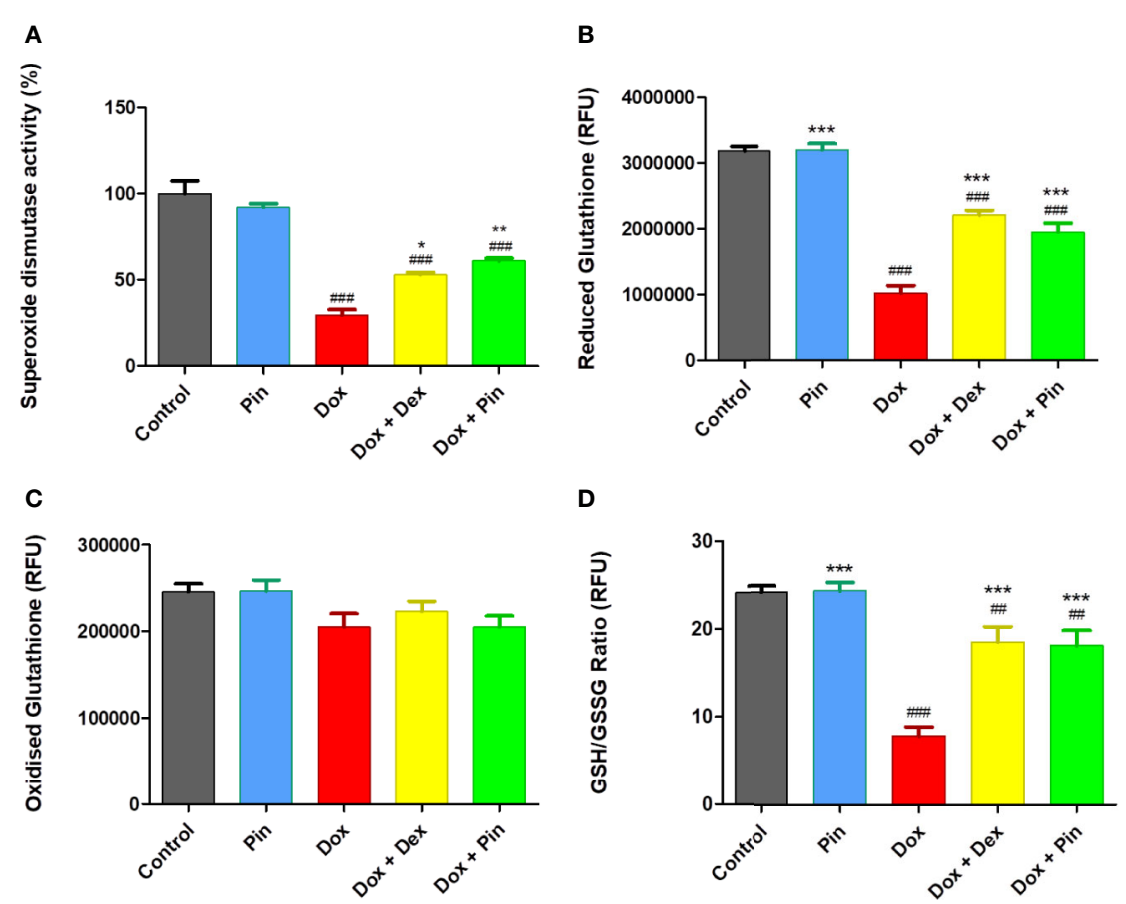

FIGURE 3 | The co-administrative effect of doxorubicin (Dox) plus pinocembrin (Pin) on the antioxidant capacity of H9c2 cells. (A) Superoxide dismutase activity, (B) reduced glutathione (GSH), (C) oxidized glutathione (GSSG) and (D) total GSH content (ratio of GSH/GSSG). H9c2 cells were treated with Dox (2 $\mu$ M), Pin $(1 \mu \mathrm{M})$, Dox $(2 \mu \mathrm{M})$ plus Pin $(1 \mu \mathrm{M})$ and Dox plus Dex $(20 \mu \mathrm{M})$ for 6 days The results were analyzed by One-way Anova, student t-tests, or non-parametric tests where applicable. Data are shown as the mean \pm SEM of 3 biological experiments with 3 technical repeats $(n=9)$. Significance is indicated as \#\# $\leq 0.01$, \#\#\# $\leq$ 0.001 versus the control; ${ }^{\star} \mathrm{p} \leq 0.05 ;{ }^{* *} \mathrm{p} \leq 0.01,{ }^{\star \star *} \mathrm{p} \leq 0.001$ versus Dox.

demonstrating the quantity of all physiological mitochondrial OC, was significantly reduced in the mitochondria's of Dox-treated cells which represents lower respiratory function relative to the control (Figures 5A, C). Similarly, this reduction was reflected in the ECAR (11.99 \pm 0.82 versus $33.34 \pm 3.14$ ) of the Dox-treated cells (Figure 5B). However, co-treatment with Dox plus Pin was able to attenuate this effect (30.46 \pm 0.91 (OCR) and $20.67 \pm 0.92$ (ECAR); $\mathrm{p} \leq 0.001$ ) (Figures 5A-C). While Dox significantly decreased ATP turnover $(1.46 \pm 0.15 ; \mathrm{p} \leq 0.01)$ (Figure $5 \mathrm{E}$ ), which is measured by ATPlinked respiration (Figure 5D) subtracted form basal OCR (Figure 5C), co-treatment with Dox plus Pin was able to improve mitochondrial ATP production (4.49 $\pm 0.61 ; \mathrm{p} \leq 0.01)$. In addition, the maximal respiration ( $M R, 30.96 \pm 1.29 ; \mathrm{p} \leq 0.001)$, as calculated by non-mitochondrial respiration subtracted from FCCP-stimulated OCR, and spare respiratory capacity (SRC, $21.22 \pm 1.35 ; \mathrm{p} \leq 0.001)$ was significantly ameliorated in cells cotreated with Dox plus Pin in comparison to the Dox-treated cells $(10.09 \pm 1.95(\mathrm{MR})$ and $7.95 \pm 0.76$ (SRC) (Figures 5F, G). The state apparent, which is an estimation of the relative mitochondrial work used by cells under basal conditions, was significantly low in Doxtreated cells suggesting a reduction in the overall flux of electrons through the respiratory chain (Table 1). However, co-treatment with Dox plus Pin was able to enhance the state apparent of these cells. We then assessed the respiratory control ratio (RCR), which represents the tightness of the coupling between respiration and oxidative phosphorylation, where the RCR value is sensitive to alterations in substrate oxidation and proton leak, but not ATP turnover. Here, co-treatment with Dox plus Pin alleviated Doxinduced impaired RCR value in the H9c2 cells indicating an elevated potential for substrate oxidation and ATP turnover (Table 1). We further observed a substantial increase in coupling efficiency after co-treatment with Dox plus Pin, which demonstrates a much higher proportion of oxygen consumed to stimulate ATP production compared with that driving proton leak (Table 1). Interestingly, co-treatment with Dox plus Pin was more effective at improving mitochondrial oxidative phosphorylation than cotreatment with Dox plus Dex (Figures 5D-G).

\section{Effect of Pinocembrin on Doxorubicin- Induced Mitochondrial Depolarization}

Considering that mitochondrial membrane dysfunction triggered by Dox plays a pivotal role in the development of Dox-induced cardiomyopathy, we assessed whether cotreatment with Dox plus Pin would preserve mitochondrial function. JC-1 staining of Dox-treated H9c2 cells revealed mitochondrial deformities with loss in structural integrity as demonstrated by increased J monomers, representing loss in mitochondrial membrane potential (MMP) $(1.69 \pm 0.13$ versus $4.21 \pm 0.11 ; \mathrm{p} \leq 0.001$ ), versus the control group (Figures $6 \mathrm{~A}, \mathbf{C}$ ). 

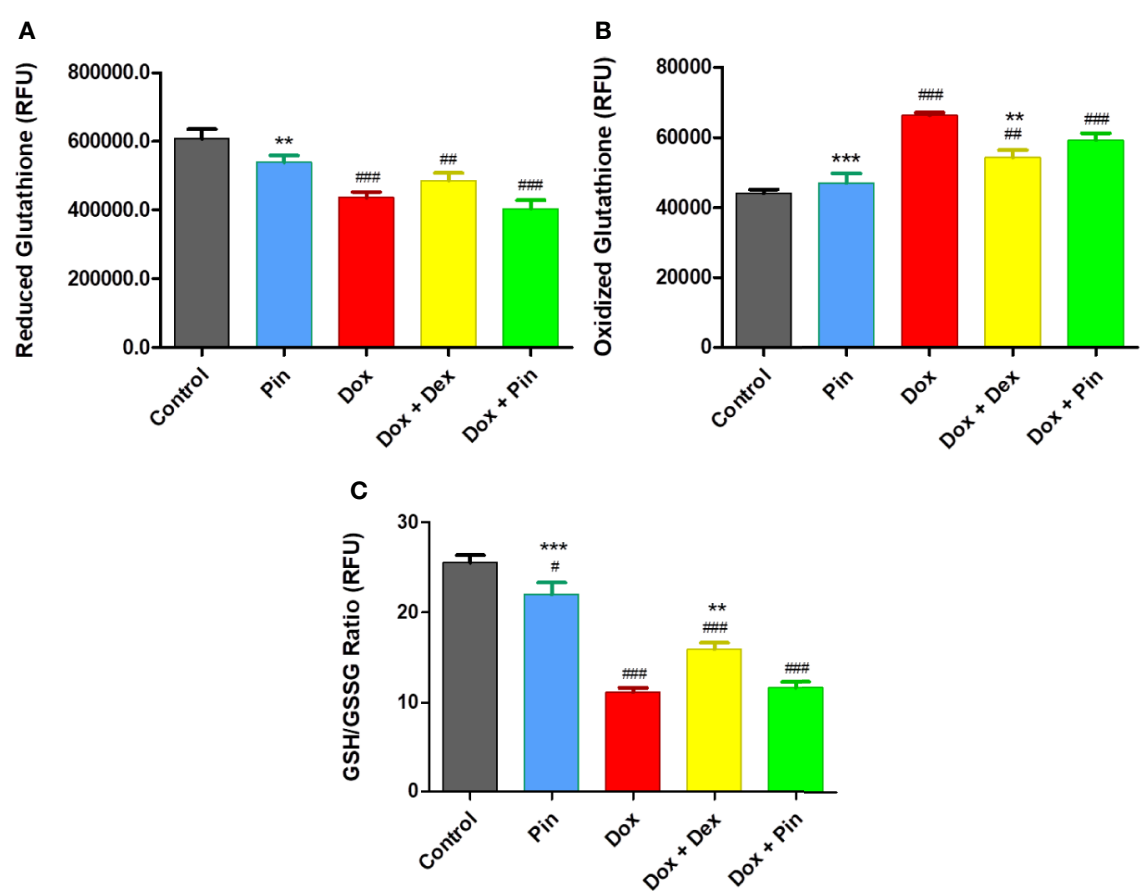

FIGURE 4 | (A) Reduced glutathione (GSH), (B) Oxidized gutathione (GSSG), (C) Total GSH content (ratio of GSH/GSSG). The co-administrative effect of doxorubicin (Dox) plus pinocembrin (Pin) on total glutathione content. To induce cytotoxicity, MCF-7 breast cancer cells were treated with Dox (2 $\mu \mathrm{M})$, Pin $(1 \mu \mathrm{M})$ or co-treated with Dox $(2 \mu \mathrm{M})$ plus Pin $(1 \mu \mathrm{M})$ and Dox $(2 \mu \mathrm{M})$ plus Dex $(20 \mu \mathrm{M})$ for 6 days. Untreated cells served as the control. The results were analyzed using One-way Anova, student t-tests, or non-parametric tests where applicable. Data are presented as the mean \pm SEM of 3 biological experiments with 3 technical repeats $(n=9)$. Significance is indicated as ${ }^{\#} \mathrm{p} \leq 0.05,{ }^{\# \#} \mathrm{p} \leq 0.01,{ }^{\# \# \#} \mathrm{p} \leq 0.001$ versus the control; ${ }^{* *} \mathrm{p} \leq 0.01,{ }^{* \star *} \mathrm{p} \leq 0.001$ versus Dox.

Loss in MMP $(0.75 \pm 0.03$ versus $3.3 \pm 0.22 ; \mathrm{p} \leq 0.001)$ was also sustained in MCF-7 cells treated with Dox (Figure 6C). Consistent with these findings, the metabolic capacity of the H9c2 cardiomyoblasts $(10.60 \pm 0.83 \%$; $\mathrm{p} \leq 0.001)$ and MCF-7 breast cancer cells $(29.12 \pm 5.22 ; \mathrm{p} \leq 0.001)$ was significantly impaired following Dox exposure (Figures 6B, D). Conversely, while the MMP $(2.14 \pm 0.15, \mathrm{p} \leq 0.05)$ and metabolic status $(26.82$ $\pm 1.99 \%$; $\leq 5.001)$ of the H9c2 cells was preserved following Dox plus Pin exposure, MCF-7 cells presented with significantly depolarized mitochondria $(1.33 \pm 0.21 ; \mathrm{p} \leq 0.20)$ and decreased metabolic status $(20.31 \pm 2.11 ; \mathrm{p} \leq 0.32)$ (Figures 6A-D). Interestingly, co-treatment with Dox plus Dex not only improved the MMP $(2.59 \pm 0.21 ; \mathrm{p} \leq 0.01)$ and metabolic capacity $(44.24 \pm 2.08 \%, \mathrm{p} \leq 0.001)$ of the H9c2 cells but, it also prevented Dox-induced mitochondrial depolarization (3.25 $\pm 0.07 ; \mathrm{p} \leq 0.001)$ (Figures 6A-D).

\section{Co-Treatment with Pinocembrin Mitigated Doxorubicin-Induced Apoptosis}

While cardiomyocyte apoptosis is a central mechanism underlying cardiac injury induced by Dox, cancer cell death is a key aspect of cancer therapy. As expected, the rate of early $(35.53 \pm 0.33 \%, \mathrm{p} \leq 0.001)$ and late $(34.19 \pm 0.61 \% ; \mathrm{p} \leq 0.001)$ apoptosis as well as necrosis was significantly elevated in Doxtreated $\mathrm{H} 9 \mathrm{c} 2$ cells and also presented with reduced number of viable cells $(24.84 \pm 0.46 ; \mathrm{p} \leq 0.001)$ (Figures 7A, B, D, F, H). Likewise, a decrease in cell viability $(7.22 \pm 1.55 ; \mathrm{p} \leq 0.001)$ with increased early $(0.81 \pm 0.17 ; \mathrm{p} \leq 0.05)$ and late $(52.93 \pm 1.128 ; \mathrm{p} \leq$ $0.001)$ apoptosis, as well as necrosis $(39.02 \pm 2.22$; $\mathrm{p} \leq 0.001)$ was observed in MCF-7 exposed to Dox (Figures 7A, C, E, G). Given that Dox plus Pin attenuated Dox-induced early $(15.740 \pm 0.00 \%$; $\mathrm{p} \leq 0.001)$ and late $(23.280 \pm 0.00 \% ; \mathrm{p} \leq 0.001)$ apoptosis, as demonstrated by an increase in the live population (50.540 \pm $2.77 \%$; $\mathrm{p} \leq 0.001)$ of the H9c2 cells, here apoptosis ( $0.80 \pm 0.05 ; \mathrm{p}$ $\geq 0.05$ ) triggered by Dox was sustained in MCF-7 cells co-treated with Dox plus Pin (Figures 7A-H). Interestingly, cancer cell death driven by Dox plus Pin was largely attributed to necrosis $(53.54 \pm 6.336 ; \mathrm{p} \leq 0.05)$ (Figure 7I). Conversely, although Dox plus Dex significantly decreased cardiomyocyte early $(22.44 \pm$ $0.50 \% ; \mathrm{p} \leq 0.001)$ and late $(13.16 \pm 0.28 \% ; \mathrm{p} \leq 0.001)$ apoptosis in $\mathrm{H} 9 \mathrm{c} 2$ cells, our findings indicate that Dex significantly reduced the rate of apoptosis $(24.01 \pm 0.24$; $\mathrm{p} \leq 0.001)$ in the MCF-7 cells. This was further supported by the observed increase in the number of viable of cells $(27.67 \pm 3.49$; $\mathrm{p} \leq 0.001)$ (Figure $7 \mathrm{C}$ ).

\section{DISCUSSION}

In the present study, we set out to investigate whether Pin could attenuate Dox-induced cardiotoxicity using an in $\mathrm{H} 9 \mathrm{c} 2$ 
A

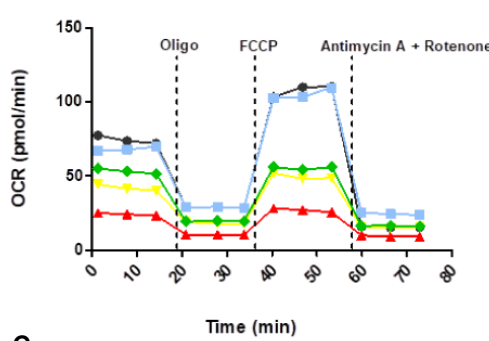

C

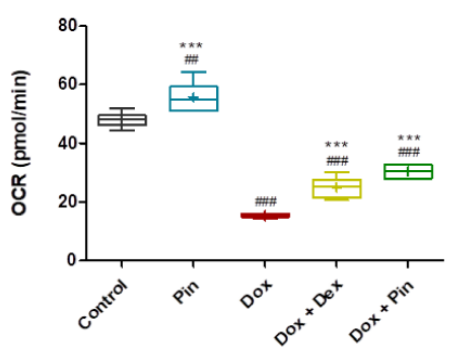

$\mathbf{F}$

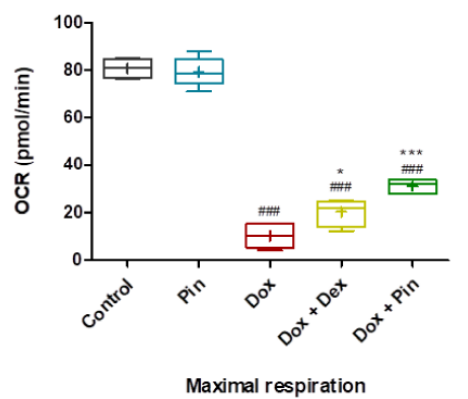

B

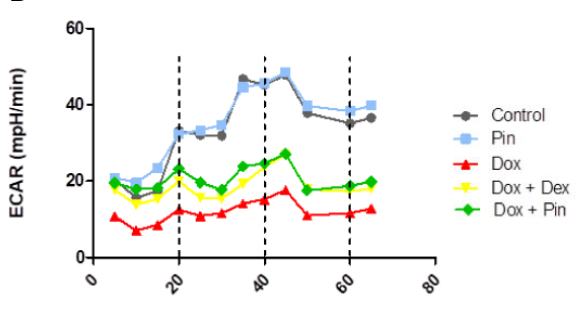

D $\quad$ Time $(\min ) \quad$ E

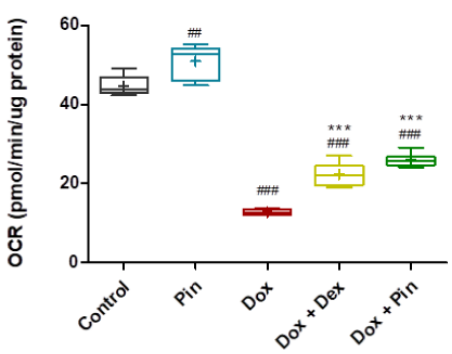

G

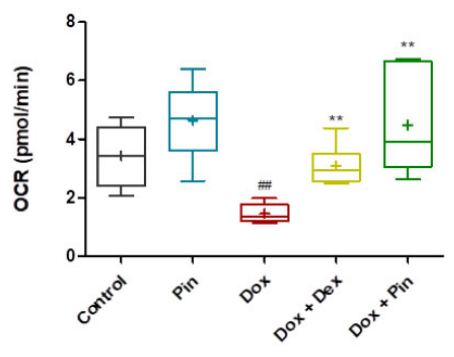

ATP turnover

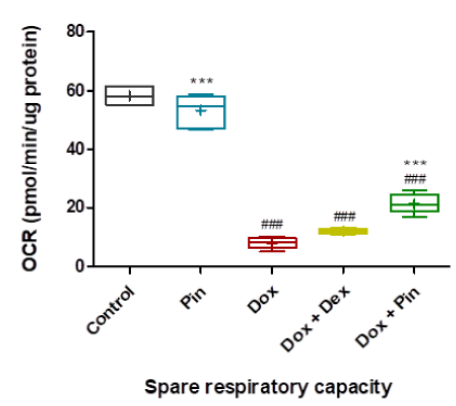

FIGURE 5 | Co-treatment with doxorubicin (Dox) plus pinocembrin (Pin) improves mitochondrial respiration. (A) Mitochondrial oxygen consumption rate (OCR) (B) extracellular acidification rate (ECAR), (C) basal respiration, (D) ATP-linked respiration, (E) ATP turnover, (F) maximal respiration and (G) spare respiratory capacity Basal respiration was acquired after subtraction of non-mitochondrial respiration. ATP turnover measured by ATP-linked respiration subtracted from the basal OCR. Maximum respiration calculated by non-mitochondrial respiration subtracted from FCCP-stimulated OCR. Coupling efficiency was calculated as the fraction of basal mitochondrial OCR used for ATP synthesis (ATP-linked OCR/basal OCR). Results were analyzed using One-way Anova, student t-tests, or non-parametric tests where applicable. Data are presented as the mean \pm SEM of 3 biological experiments with 6 technical repeats $(n=9)$. Significance is indicated as $\# \# \leq 0.01$, \#\#\# $p \leq$ 0.001 versus the control; ${ }^{*} p<0.05,{ }^{* *} p \leq 0.01,{ }^{* * *} p \leq 0.001$ versus Dox.

TABLE 1 | Normalized respiratory flux control ratios.

Normalized respiratory flux ratios \begin{tabular}{lrr}
\cline { 2 - 3 } & \multicolumn{1}{c}{ Control } \\
\hline State apparent & $3.60 \pm 0.01$ & $3.49 \pm 0.02$ \\
Respiratory control ratio (RCR) & $39.27 \pm 3.94$ & $33.67 \pm$ \\
Coupling efficiency & $0.93 \pm 0.01$ & $0.91 \pm 0.02$ \\
\hline The state apparent, respiratory control ratio (RCR) and coupling efficiency of H9c2 cells in \\
mitochondrial parameters presented in Figure 5. Data represents mean \pm SEM; $n=6$. Signif \\
0.001 versus Dox. \\
\multicolumn{2}{c}{ cardiomyoblast in vitro model. This model was selected based on } \\
current literature which indicates that H9c2 cells are a suitable in
\end{tabular} vitro model to study various forms of cardiotoxicity such as that inferred by Dox administration (Catanzaro et al., 2019; Dallons et al., 2020; Faridvand et al., 2020; Hu et al., 2020).
Mechanistically, the pathophysiology of Dox-induced cardiotoxicity is said to be driven by increased oxidative stress, loss in mitochondrial membrane potential and aggravated apoptosis (Conklin, 2005; Carvalho et al., 2009; McGowan et al., 2017; Shabalala et al., 2017). Although there is an obvious need to 


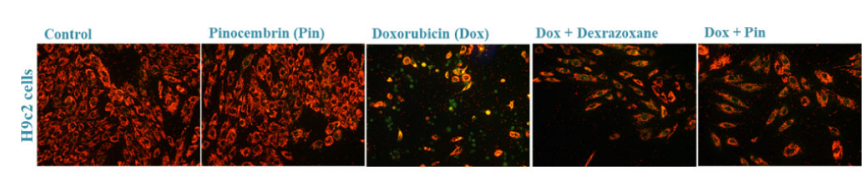

A

B

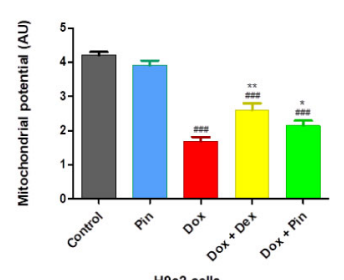

B

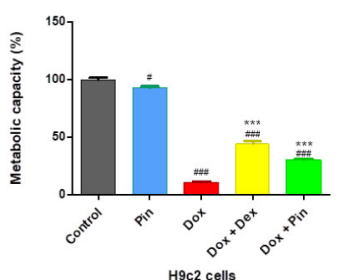

H9c2 cells
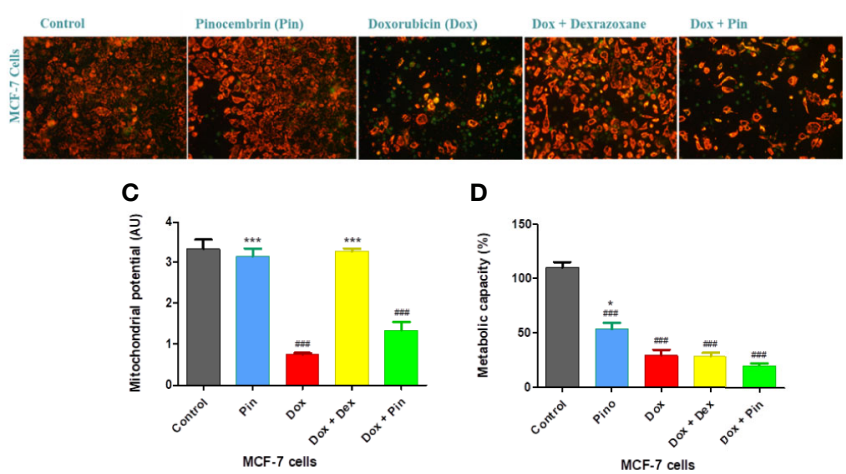

D

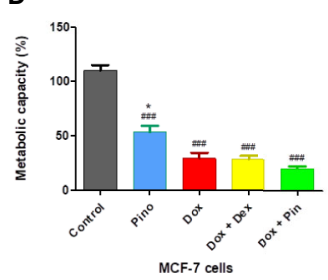

FIGURE 6 | The co-administrative effect of doxorubicin (Dox) plus pinocembrin (Pin) on the mitochondrial integrity of the H9c2 cardiomyoblasts and MCF-7 breast cancer cells. (A) JC-1 staining and mitochondrial membrane potential (MMP) of H9c2 cells, (B) metabolic activity of H9c2 cells, (C) JC-1 staining and MMP of MCF-7 cells and (D) metabolic capacity of MCF-7. Results were analyzed using One-way Anova, student t-tests, or non-parametric tests where applicable. Data are shown as the mean \pm SEM of 3 biological experiments with 4 technical repeats $(n=12)$. Significance is indicated as ${ }^{\#} p \leq 0.05$, $\# \# \# \leq 0.001$ versus the control; ${ }^{*} p \leq 0.05$, ${ }^{\star \star} \mathrm{p} \leq 0.01,{ }^{\star \star *} \mathrm{p} \leq 0.001$ versus Dox.

investigate new cardioprotective agents, it is imperative to clarify whether or not newly developed therapeutic adjuncts interact with cancer therapy. Indeed, Yasueda and colleagues (2016) argued that while such therapeutic agents may mitigate the adverse effects of chemotherapy, they could antagonize the antitumor effects of drugs like Dox. Thus, we also assessed the effect of Pin on the efficacy of Dox in an MCF-7 breast cancer environment.

Generally, the cardiac muscle is considered a chief target for Dox-induced oxidative stress due to its naturally low antioxidant enzyme activity (Zhang and Wang, 2007). In the current study, chronic Dox exposure led to accelerated ROS production and lipidperoxidation, which was concomitant with the observed reduction in SOD and GSH activity. We postulate that the perceived GSH deficiency could be due to GSH consumption in the interactions of Dox-induced free radicals with bio-membrane and the subsequent lipid peroxidation in the H9c2 cells (Zhang et al., 2019). However, Pin as a co-treatment was able to mitigate Dox-induced oxidative stress by boosting the antioxidant capacity of the H9c2 cells whilst decreasing ROS and MDA levels. As previously stated, cancer cells have the ability to take advantage of the upregulated antioxidant defense system to circumvent ROS-mediated tumor cell damage (Thyagarajan and Sahu, 2018). Here, co-treatment with Pin did not enhance the antioxidant activity of the Dox-treated MCF-7 cells, suggesting that Pin could be used as a potent ROS scavenger against Dox-mediated oxidative stress in the cardiac muscle without protecting the cancer cells. In contrast, MCF-7 cells co-treated with Dex presented with significantly improved antioxidant levels.

The high-energy-demand nature of the cardiac muscle requires that there be sufficient ATP production to sustain normal cardiac contraction (Werner et al., 2016). Studies have shown that Dox administration is associated with reduced metabolic activity and impaired cardiomyocyte viability (Chakrabarti et al., 2012). Similarly, data demonstrated in this study supported this notion as $\mathrm{H} 9 \mathrm{c} 2$ cells subjected to chronic Dox conditions presented with reduced metabolic capacity leading to a significant loss in cell viability. Interestingly, Dox-induced loss in metabolic levels in MCF-7 cells was not affected by Pin administration. Pertaining to mitochondrial bioenergetics, in response to Dox exposure, we found that Pin was able to ameliorate mitochondrial OCR through enhanced oxidative phosphorylation in the H9c2 cells. These findings were in accordance with an in vivo study conducted by $\mathrm{Wu}$ and colleagues (2016) demonstrating that Dox significantly impaired mitochondrial function and ATP production in male rats. In addition, co-treatment with Pin significantly attenuated Doxinduced mitochondrial depolarization as indicated by the improved MMP of the H9c2 cells. Interestingly, while Pin preserved the loss in 


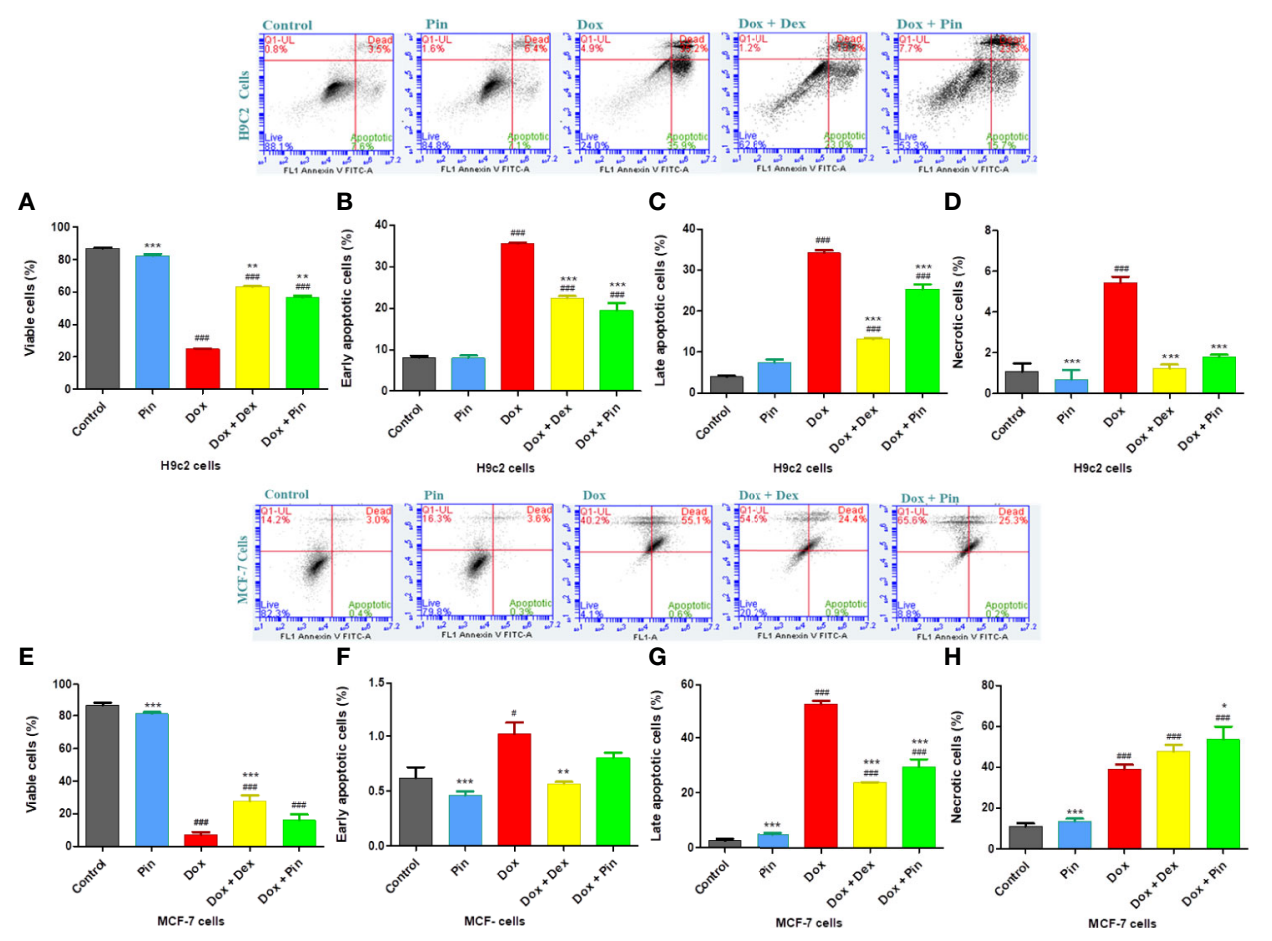

FIGURE 7 | The effect of pinocembrin (Pin) on Doxorubicin-induced apoptosis. (A) Viable, (B) early apoptotic, (C) late apoptotic, and (D) necrotic H9c2 cells. (E) Viable MCF7 breast cancer cells, (F) early apoptotic, (G) late apoptotic, and (H) necrotic MCF-7 cells. Annexin V and propidium iodide (PI) staining was evaluated using a BD Accuri C6. Upper right quadrant: Demonstrates cells showing Annexin V and PI positive and late apoptotic. Lower right quadrant: Cells that are Annexin V positive but are PI negative and are early apoptotic. Lower left quadrant: Consists of viable cells that are both Annexin V and PI negative. Upper left quadrant: Cells stained PI positive and are considered necrotic. The results were analyzed using One-way Anova, student t-tests, or non-parametric tests where applicable. Data are shown as the mean \pm SEM of 3 biological experiments with 3 technical repeats $(n=9)$. Significance is indicated as ${ }^{\# \# \#} p \leq 0.001$ versus the control; ${ }^{* *} p \leq 0.01,{ }^{\star \star \star} p \leq 0.001$ versus Dox.

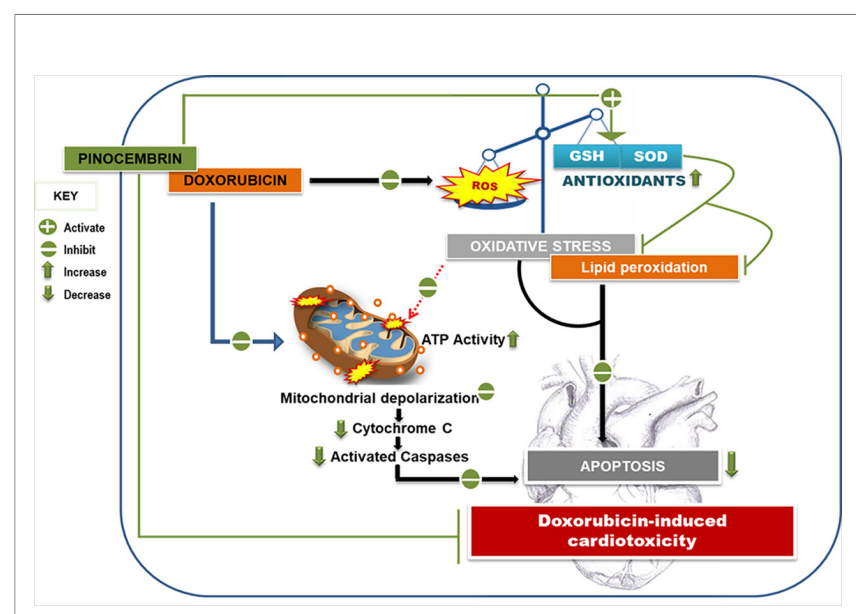

FIGURE 8 | Pinocembrin attenuates Doxorubicin-induced cardiotoxicity. Pinocembrin as adjunct to the chemotherapeutic drug Doxorubicin protects H9c2 cardiomyoblasts from Doxorubicin-mediated oxidative stress and lipid peroxidation by boosting the activity of superoxide dismutase and the ratio of reduced glutathione to oxidized glutathione content. This increase in antioxidant capacity thereby ameliorates the mitochondrial membrane potential of the heart cells and protects against resultant apoptosis. mitochondrial function and integrity in the MCF-7 cells, Dex significantly hindered the mitochondrial damage ensued by Dox on these cells.

In a clinical setting, Zhao and Zhang (2017) demonstrated that Dox administration activated cell death pathways in the hearts of cancer patients within hours of intravenous administration. Likewise, Subbarao and colleagues (2018) reported that H9c2 cardiomyoblasts treated with Dox had a significant increase in late apoptotic cells. Accordingly, our findings revealed that chronic Dox exposure significantly accelerates the rate of apoptosis in the cardiac and breast cancer cells. However, the results also showed that while Pin mitigates Dox-induced apoptosis in the H9c2 cells, it is able improve the apoptotic and necrotic status of inferred by Dox on the MCF-7 cells, which is a key aspect in cancer cell therapy. Although Dex is vastly used in chemotherapeutic regimens with Dox, data presented in this study suggests that Dex might indeed have some effect on Dox, as demonstrated by the decreased rate of metastatic MCF-7 apoptosis.

In conclusion, the results presented in this study, showed for the first time, that the co-administrative use of Pin prevents Doxinduced cardiotoxicity by improving the antioxidant enzyme activity and mitochondrial bioenergetics of the H9c2 cells. Pin 
further reduced Dox-mediated apoptosis which is a key aspect in the prevention of cardiovascular dysfunction (Figure 8). In addition, our findings indicate that while Pin does in fact have cardioprotective properties in vitro (Figure 8), its therapeutic effect appear to not have a limiting effect on the chemotherapeutic potential of Dox when tested on MCF-7 cells. Though the findings obtained in the current study are very encouraging, further investigation using in vivo models are required to confirm the prophylactic effect of Pin against Dox-induced cardiotoxicity.

\section{DATA AVAILABILITY STATEMENT}

All datasets generated for this study are included in the article/ supplementary material.

\section{AUTHOR CONTRIBUTIONS}

NS conducted all the experimental work, with some assistance from MM and SR. NS wrote and designed the manuscript. NS and RJ equally contributed to the conceptualization of the manuscript. RJ, NS, MM, LM, DV, SR, and BH approved the final draft of the manuscript.

\section{FUNDING}

The work reported herein was made possible through funding by the South African Medical Research Council (SAMRC) through its Division of Research Capacity Development under the Internship Scholarship Programme. The content hereof is the sole responsibility of the authors and does not necessarily represent the official views of the SAMRC. The authors would also like to acknowledge the financial support from the SAMRC, Biomedical Research and Innovation Platform (baseline funding) through funding received from the South African National Treasury. Lastly, we would also like to acknowledge the National Research Foundation for the financial support [Thuthuka Grant (UID107261)]. The authors would also like to thank BioPharm, New Zealand, for supplying the treatment (pinocembrin).

\section{REFERENCES}

Ahmeda, L. A., Rizk, S. M., and EL-Maraghy, S. A. (2017). Pinocembrin ex vivo preconditioning improves the therapeutic efficacy of endothelial progenitor cells in monocrotaline-induced pulmonary hypertension in rats. Biochem. Pharmacol. 138, 193-204. doi: 10.1016/j.bcp.2017.04.024

Bast, A., Kaiserová, H. H., den Hartog, G. J. M., Haenen, G. R. M. M., and van der Vijgh, W. J. F. (2007). Protectors against doxorubicin-induced cardiotoxicity: Flavonoids. Cell Biol. Toxicol. 23 (1), 39-47. doi: 10.1007/s10565-006-0139-4

Bernardes, S. S., de Souza-Neto, F. P., Ramalho, L. N., Derossi, D. R., Guarnier, F. A., da Silva, C. F., et al. (2015). Systemic oxidative profile after tumor removal and the tumor microenvironment in melanoma patients. Cancer Lett. 361 (2), 226-232. doi: 10.1016/j.canlet.2015.03.007

Bhattacharyya, S., Md Sakib Hossain, D., Mohanty, S., Sankar Sen, G., Chattopadhyay, S., Banerjee, S., et al. (2010). Curcumin reverses T cellmediated adaptive immune dysfunctions in tumor-bearing hosts. Cell. Mol. Immunol. 7 (4), 306-315. doi: 10.1038/cmi.2010.11

Borriello, M., Iannuzzi, C., and Sirangelo, I. (2019). Pinocembrin Protects from AGE-Induced Cytotoxicity and Inhibits Non-Enzymatic Glycation in Human Insulin. Cells 8, 385. doi: 10.3390/cells8050385

Bose, S., Panda, A. K., Mukherjee, S., and Sa, G. (2015). Curcumin and tumor immune-editing: resurrecting the immune system. Cell Div. 10, 6. doi: 10.1186/ s13008-015-0012-z

Carvalho, C., Santos, R., Cardoso, S., Correia, S., Oliveira, P., Santos, M., et al. (2009). Doxorubicin: The Good, the Bad and the Ugly Effect. Curr. Med. Chem. 16, 3267-3285. doi: 10.2174/092986709788803312

Catanzaro, M. P., Weiner, A., Kaminaris, A., Li, C., Cai, F., Zhao, F., et al. (2019). Doxorubicin-induced cardiomyocyte death is mediated by unchecked mitochondrial fission and mitophagy. FASEB J. 33 (10), 11096-11108. doi: 10.1096/ff.201802663R

Chakrabarti, L., Abou-Antoun, T., Vukmanovic, S., and Sandler, A. D. (2012). Reversible adaptive plasticity: A mechanism for neuroblastoma cell heterogeneity and chemo-resistance. Front. Oncol. 2, 82. doi: 10.3389/fonc.2012.00082

Chang, D., Li, H., Qian, C., and Wang, Y. (2019). DiOHF Protects Against Doxorubicin-Induced Cardiotoxicity Through ERK1 Signaling Pathway. Front. Pharmacol. 10:1081. doi: 10.3389/fphar.2019.01081

Conklin, K. A. (2005). Coenzyme Q10 for prevention of anthracycline-induced cardiotoxicity. Integr. Cancer Ther. 4 (2), 110-130. doi: 10.1177/1534735405276191

Dallons, M., Schepkens, C., Dupuis, A., Tagliatti, V., and Colet, J. M. (2020). New Insights About Doxorubicin-Induced Toxicity to CardiomyoblastDerived H9C2 Cells and Dexrazoxane Cytoprotective Effect: Contribution of In Vitro 1H-NMR Metabonomics. Front. Pharmacol. 11:79. doi: 10.3389/ fphar.2020.00079

Estrada, O., Di Giulio, C., Dorta-Ledezma, R., Gonzalez-Mujica, F., Motta, N., Zea, E., et al. (2020) A Compound Isolated from Phyllanthus tenellus Demonstrates Metabolic and Vascular Effects In Vitro. Planta Med. 86, 78-84. doi: 10.1055/a1019-9401

Faridvand, Y., Haddadi, P., Vahedian, V., Nozari, S., Nejabati, H. R., Pezeshkian, M., et al. (2020). Human Amnion Membrane Proteins Prevent DoxorubicinInduced Oxidative Stress Injury and Apoptosis in Rat H9c2 Cardiomyocytes. Cardiovasc. Toxicol. 20, 370-379. doi: 10.1007/s12012-020-09564-8

Ganatra, S., Nohria, A., Shah, S., Groarke, J. D., Sharma, A., Venesy, D., et al. (2019). Upfront dexrazoxane for the reduction of anthracycline-induced cardiotoxicity in adults with preexisting cardiomyopathy and cancer: a consecutive case series. Cardio-Oncology 5, 1-12. doi: 10.1186/s40959-019-0036-7

Harake, D., Franco, V. I., Henkel, J. M., Miller, T. L., and Lipshultz, S. E. (2012). Cardiotoxicity in childhood cancer survivors: Strategies for prevention and management. Future Cardiol. 8 (4), 647-670. doi: 10.2217/fca.12.44

Hu, Y. H., Liu, J., Lu, J., Wang, P. X., Chen, J. X., Guo, Y., et al. (2020). sFRP1 protects $\mathrm{H} 9 \mathrm{c} 2$ cardiac myoblasts from doxorubicin-induced apoptosis by inhibiting the Wnt/PCP-JNK pathway. Acta Pharmacol. Sin. 0, 1-8. doi: 10.1038/s41401-020-0364-Z

Koleini, N., and Kardami, E. (2017). Autophagy and mitophagy in the context of doxorubicin-induced cardiotoxicity. Oncotarget. 8 (28), 46663-46680. doi: 10.18632/oncotarget.16944

Kosty, M. P., Herndon, J. E., Vogelzang, N. J., Kindler, H. L., and Green, M. R. (2001). High-dose doxorubicin, dexrazoxane, and GM-CSF in malignant mesothelioma: A phase II study - Cancer and Leukemia Group B 9631. Lung Cancer 34, 289-295. doi: 10.1016/S0169-5002(01)00250-1

Levis, B. E., Binkley, P. F., and Shapiro, C. L. (2017). Cardiotoxic effects of anthracycline-based therapy: what is the evidence and what are the potential harms? Lancet Oncol. 18, e445-e456. doi: 10.1016/S1470-2045(17)30535-1

Lungkaphin, A., Pongchaidecha, A., Palee, S., Arjinajarn, P., Pompimon, W., and Chattipakorn, N. (2015). Pinocembrin reduces cardiac arrhythmia and infarct size in rats subjected to acute myocardial ischemia/reperfusion. Appl. Physiol. Nutr. Metab. 40 (10), 1031-1037. doi: 10.1139/apnm-2015-0108 
McGowan, J. V., Chung, R., Maulik, A., Piotrowska, I., Walker, J. M., and Yellon, D. M. (2017). Anthracycline Chemotherapy and Cardiotoxicity. Cardiovasc. Drugs Ther. 31, 63-75. doi: 10.1007/s10557-016-6711-0

Raninga, P. V., Trapani, G. D., and Tonissen, K. F. (2014). Cross Talk between Two Antioxidant Systems, Thioredoxin and DJ-1: Consequences for Cancer. Oncoscience 1 (1), 95-110. doi: 10.18632/oncoscience.12

Rasul, A., Millimouno, F. M., Ali Eltayb, W., Ali, M., Li, J., and Li, X. (2013). Pinocembrin: A novel natural compound with versatile pharmacological and biological activities. BioMed. Res. Int. 2013, 379850. doi: 10.1155/2013/379850

Rharass, T., Gbankoto, A., Canal, C., Kursunluoglu, G., Bijoux, A., Panakova, D., et al. (2016). Oxidative stress does not play a primary role in the toxicity induced with clinical doses of doxorubicin in myocardial H9c2 cells. Mol. Cell Biochem. 413, 199-215. doi: 10.1007/s11010-016-2653-x

Saad, M. A., Abdel Salam, R. M., Kenawy, S. A., and Attia, A. S. (2015). Pinocembrin attenuates hippocampal inflammation, oxidative perturbations and apoptosis in a rat model of global cerebral ischemia reperfusion. Pharmacol. Rep. 67, 115-122. doi: 10.1016/j.pharep.2014.08.014

Shabalala, S., Louw, J., Muller, C. J. F., and Johnson, R. (2017). Polyphenols, autophagy and doxorubicin-induced cardiotoxicity. Life Sci. 180, 160-170. doi: 10.1016/j.lfs.2017.05.003

Singal, P. K., and Kirshenbaum, L. A. (1990). A relative deficit in antioxidant reserve may contribute in cardiac failure. Can. J. Cardiol. 6 (2), 47-49.

Subbarao, R. B., Ok, S., Lee, S., Kang, D., Kim, E., Ji-Yoon Kim, J., et al. (2018). Lipid Emulsion Inhibits the Late Apoptosis/Cardiotoxicity Induced by Doxorubicin in Rat Cardiomyoblasts. Cells 7 (10), 144. doi: 10.3390/cells7100144

Sun, X., Wan, L., Yang, Q., Huo, Y., Han, Y., and Guo, C. (2007). Scutellarin protects against doxorubicin-induced acute cardiotoxicity and regulates its accumulation in the heart. Arch. Pharmacol. Res. 40 (7), 875-883. doi: 10.1007/ s12272-017-0907-0

Tahover, E., Segal, A., Isacson, R., Rosengarten, O., Grenader, T., Gips, M., et al. (2017). Dexrazoxane added to doxorubicin-based adjuvant chemotherapy of breast cancer. Anticancer Drugs 28, 787-794. doi: 10.1097/CAD.0000000000000514

Thyagarajan, A., and Sahu, R. P. (2018). Potential Contributions of Antioxidants to Cancer Therapy: Immunomodulation and Radiosensitization. Integr. Cancer Ther. 17 (2), 210-216. doi: 10.1177/1534735416681639

Vachhani, P., Shin, S., Baron, J., Thompson, J. E., Wetzler, M., Griffiths, E. A., et al. (2017). Dexrazoxane for cardioprotection in older adults with acute myeloid leukemia. Leuk Res. Rep. 25 (21), 3179. doi: 10.1016/j.lrr.2017.04.001

van Dalen, E. C., Caron, H. N., Dickinson, H. O., and Kremer, L. C. M. (2011). Cardioprotective interventions for cancer patients receiving anthracyclines. Cochrane Database Syst. Rev. 6, CD003917. doi: 10.1002/14651858.CD003917.pub4
Vantangoli, M. M., Madnick, S. J., Huse, S. M., Weston, P., and Boekelheide, K. (2015) MCF-7 Human Breast Cancer Cells Form Differentiated Microtissues in Scaffold-Free Hydrogels. PLOS ONE doi: 10.1371/journal.pone.0135426

Werner, C., Doenst, T., and Schwarzer, M. (2016). Chapter 4-Metabolic Pathways and Cycles. The Scientist's Guide to Cardiac Metabolism (1st ed. pp 39-55). (San Diego, United States: Elsevier Science Publishing Co Inc.)

Wu, R., Wang, H., Yu, H., Cui, X., Xu, M., Xu, X., et al. (2016). Doxorubicin toxicity changes myocardial energy metabolism in rats. Chem.-Biol. Interact. 244, 149-158. doi: 10.1016/j.cbi.2015.12.010

Yasueda, A., Urushima, H., and Ito, T. (2016). Efficacy and Interaction of Antioxidant Supplements as Adjuvant Therapy in Cancer Treatment. Integr. Cancer Ther. 15 (1), 17-39. doi: 10.1177/1534735415610427

Zhang, H. S., and Wang, S. Q. (2007). Nrf2 is involved in the effect of tanshinone IIA on intracellular redox status in human aortic smooth muscle cells. Biochem. Pharmacol. 73 (9), 1358-1366. doi: 10.1016/j.bcp.2007.01.004

Zhang, Q., Yang, J., and Zhang, H. (2019). Carvedilol (CAR) combined with carnosic acid (CAA) attenuates doxorubicin-induced cardiotoxicity by suppressing excessive oxidative stress, inflammation, apoptosis and autophagy. Biomed. Pharmacother. 109, 71-83. doi: 10.1016/ j.biopha.2018.07.037

Zhao, L., and Zhang, B. (2017). Doxorubicin induces cardiotoxicity through upregulation of death receptors mediated apoptosis in cardiomyocytes. Sci. Rep. 7, 44735. doi: 10.1038/srep44735

Zilinyi, R., Czompa, A., Czegledi, A., Gajtko, A., Pituk, D., Lekli, I., et al. (2018). The cardioprotective effect of metformin in doxorubicin-induced cardiotoxicity: The role of autophagy. Molecules. 23 (5), 1184. doi: 10.3390/ molecules 23051184

Conflict of Interest: RB was employed by BioPharm Limited, NZ.

The remaining authors declare that the research was conducted in the absence of any commercial or financial relationships that could be construed as a potential conflict of interest.

Copyright (c) 2020 Sangweni, Moremane, Riedel, van Vuuren, Huisamen, Mabasa, Barry and Johnson. This is an open-access article distributed under the terms of the Creative Commons Attribution License (CC BY). The use, distribution or reproduction in other forums is permitted, provided the original author $(s)$ and the copyright owner(s) are credited and that the original publication in this journal is cited, in accordance with accepted academic practice. No use, distribution or reproduction is permitted which does not comply with these terms. 